\title{
Heroin-Induced Toxic Leukoencephalopathy
}

\author{
Robin van Steenhoven, Giorgos Karas, Poen Tan, Henry Weinstein \\ Department of Neurology, OLVG, Amsterdam, The Netherlands \\ Email: r.vansteenhoven@olvg.nl
}

How to cite this paper: van Steenhoven, R., Karas, G., Tan, P. and Weinstein, H. (2017) Heroin-Induced Toxic Leukoencephalopathy. Case Reports in Clinical Medicine, 6, 227-230.

https://doi.org/10.4236/crcm.2017.68024

Received: May 30, 2017

Accepted: August 6, 2017

Published: August 9, 2017

Copyright ( $) 2017$ by authors and Scientific Research Publishing Inc. This work is licensed under the Creative Commons Attribution International License (CC BY 4.0).

http://creativecommons.org/licenses/by/4.0/

(c) †) Open Access

\begin{abstract}
Toxic leukoencephalopathy is an important complication of heroin abuse and has mostly been described after inhaling heroin vapor, known as "chasing the dragon syndrome" or heroin inhalation leukoencephalopathy (HIL). We present a 51 year-old male patient with toxic leukoencephalopathy following intranasal administration of heroin.
\end{abstract}

\section{Keywords}

Clinical Neurology, Neuroradiology, Toxicology, Opiates, Toxic Leukoencephalopathy

\section{Case Presentation}

A 51-year-old man with a history of depression was admitted after intoxication with intranasal heroin, complicated by rhabdomyolysis and acute kidney failure. On admission, vital signs were normal and no episode of coma or prolonged hypoxia had been observed. He fully recovered and had been discharged home six days later. Four weeks later the patient was represented to the ER of this hospital by his family with progressive behavioral changes starting one week before presentation. The family reported progressive apathy, confusion, difficulty with walking and incontinence for urine. On presentation the patient was agitated with impaired attention and disorientation in time and place. Spontaneous speech production was reduced and he only followed simple commands. Further neurological examination demonstrated remarkable, predominantly upper limb rigidity and bradykinesia. The patient deteriorated the following day and loss of spontaneous speech and worsening of the hypertonia occurred.

Magnetic resonance imaging (MRI) of the brain showed, on T2-weighted images, extensive confluent, diffuse white matter hyperintensities in the frontal, parietal and temporal region of both hemispheres (Figure 1). The U-fibers, corpus callosum and cerebellum and other infratentorial structures were spared. 
The abnormalities were bright on diffusion weighted imaging (DWI)-weighted images with low signal in corresponding regions on the apparent diffusion coefficient map (ADC). Extensive ancillary investigations were performed. An infectious cause was ruled out by the absence of CSF pleiocytosis and negative cultures and viral studies in blood and CSF. Autoantibodies and inflammatory parameters were normal. Blood tests revealed no metabolic disturbances, including normal activity of arylsulfatase A and normal concentration of very long chain fatty acids (VLCFA). Toxicology screening in the urine was positive for opiates. The absence of evidence for any other underlying cause, the remarkable temporal relation of the onset of symptoms four weeks after the intoxication with heroin and the MRI-images of the brain led to the clinical diagnosis of toxic leukoencephalopathy.

The patient was treated with supportive care and transferred to a nursing home. After six months neurological examination was completely normal and no motor signs were found. Neuropsychological testing demonstrated impaired attention and signs of behavioral deficits. Repeat imaging of the brain showed improvement of the supratentorial white matter hyperintensities (Figure 1).

\section{Discussion}

Heroin-induced toxic leukoencephalopathy has been frequently reported after inhaling heroin vapor, known as heroin inhalation leukoencephalopathy (HIL) and is characterized by three clinical stages [1] [2]. The first stage manifests as a

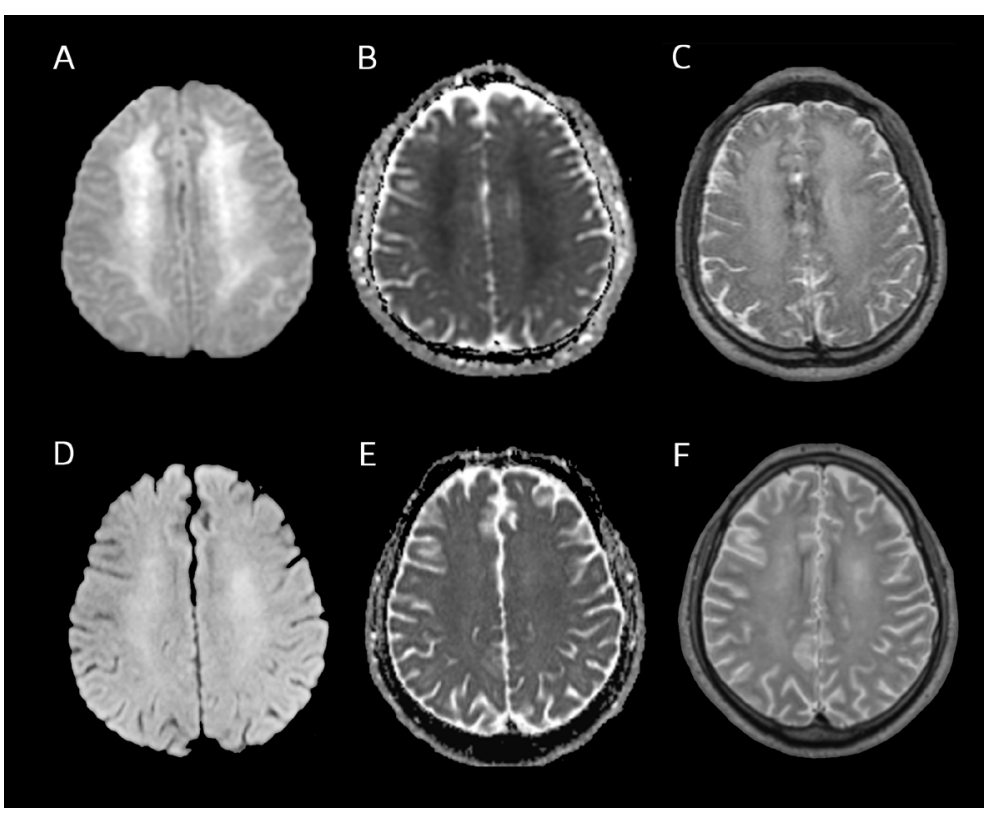

Figure 1. (A)-(C) Brain MRI on admission. Axial diffusion-weighted imaging (DWI) (A), apparent diffusion coefficient imaging (ADC) (B), and T2-weighted images (C) showing diffuse leukoencephalopathy in both cerebral hemispheres. (D)-(F) Brain MRI six months after admission. Axial diffusion-weighted imaging (DWI) (D), apparent diffusion coefficient imaging (ADC) (E), and T2-weighted images (F) showing improvement of the leukoencephalopathy in both cerebral hemispheres. 
cerebellar syndrome with gait and limb ataxia. In the second stage the ataxia worsens and spastic paresis and myoclonus may occur. The terminal stage is characterized by hypotonic paresis, akinetic mutism and stretch spasms [2]. Characteristic radiologic findings of heroin inhalation leukoencephalopathy are lesions of the cerebellar and posterior white matter and the posterior limb of the internal capsule on T2-weighted MR images [2] [3]. We present a case of toxic leukoencephalopathy following intranasal administration of heroin, which to our knowledge has only been described two times previously [4] [5]. MRI of the brain demonstrated bilateral supratentorial lesions without involvement of the brainstem and cerebellum, in contrast to the infratentorial lesions documented in heroin inhalation leukoencephalopathy. The patient presented after a latency period of four weeks and partial clinical recovery was observed after six months.

Given the biphasic course of symptoms and supratentorial white matter hyperintensities on MRI, an etiologic hypoxic component, which has been described in delayed posthypoxic leukoencephalopathy (DPHL), however, cannot be excluded [2]. This syndrome is characterized by complete or near-complete recovery after an acute event of consciousness or coma, followed by neuropsychiatric deterioration days to weeks later [2]. Classic MRI findings are diffuse hyperintense lesions of the periventriculair white matter with sparing of the structures in the fossa posterior [2]. Delayed posthypoxic leukoencephalopathy has been described in several cases of after drug overdose, including heroin, complicated by an hypoxic insult [2] [6]. The prognosis is variable and full recovery has been described [6].

Although clinical and radiological symptoms in our patient are compatible with a syndrome of delayed posthypoxic leukoencephalopathy, a syndrome of heroin-induced toxic leukoencephalopathy to our opinion seems more probable considering the lack of an observed coma or a period of prolonged hypoxia in this patient.

\section{Acknowledgements}

None.

\section{References}

[1] Wolters, E.C., van Wijngaarden, G.K., Stam, F.C., et al. (1982) Leucoencephalopathy after Inhaling "Heroin" Pyrolysate. Lancet, 2, 1233-1237. https://doi.org/10.1016/S0140-6736(82)90101-5

[2] Tormoehlen, L.M. (2013) Toxic Leukoencephalopathies. Psychiatric Clinics of North America, 36, 277-292. https://doi.org/10.1016/j.psc.2013.02.006

[3] Hagel, J., Andrews, G., Vertinsky, T., et al. (2005) "Chasing the Dragon"-Imaging of Heroin Inhalation Leukoencephalopathy. Canadian Association of Radiologists Journal, 56, 199-203.

[4] Hattingen, E., Adelmann, M., Nichtweiß, M., et al. (2010) Toxic Leukoencephalopathy after Heroin Abuse without Heroin Vapor Inhalation: MR Imaging and Clinical Features in Three Patients. Clinical Neuroradiology, 20, 48-53. https://doi.org/10.1007/s00062-010-0022-9 
[5] Drouet, A., Lamboley, J.L., Cotton, F., et al. (2012) Toxic Leucoencephalopathy after Use of Sniffed Heroin, an Unrecognized Form of Beneficial Evolution. Revista De Neurologia (Paris), 168, 57-64.

[6] Betts, A.M., Ritter, J.L. and Kubal, W.S. (2012) Reversible Delayed Posthypoxic Leukoencephalopathy after Drug Overdose: MRI Findings in a Collection of Patients. Emergency Radiology, 19, 165-173.

https://doi.org/10.1007/s10140-011-1013-0

\section{Scientific Research Publishing}

Submit or recommend next manuscript to SCIRP and we will provide best service for you:

Accepting pre-submission inquiries through Email, Facebook, LinkedIn, Twitter, etc. A wide selection of journals (inclusive of 9 subjects, more than 200 journals)

Providing 24-hour high-quality service

User-friendly online submission system

Fair and swift peer-review system

Efficient typesetting and proofreading procedure

Display of the result of downloads and visits, as well as the number of cited articles

Maximum dissemination of your research work

Submit your manuscript at: http://papersubmission.scirp.org/

Or contact crcm@scirp.org 